\title{
Statistical Evaluation of Rehabilitation to the Disabled Elderly based Takizawa-Program
}

\author{
Kenji Ushizawa $^{1} \cdot$ Shigeo Takizawa $^{2} \cdot$ Hiroshi Nagasawa $^{3}$ \\ Mitsuyo Makita $^{4} \cdot$ Tetsuhiko Kimura $^{5} \cdot$ Kyoko Takizawa $^{6}$ \\ ${ }^{1}$ School of Management and Information Science, SANNO University \\ ${ }^{2}$ Biophilia Institute Inc. \\ ${ }^{3}$ Kanagawa University of Human Services \\ ${ }^{4}$ Niigata University of Health and Welfare \\ ${ }^{5}$ International University Health and Welfare Graduate School \\ ${ }^{6}$ Shonan-no-oka Health care facility
}

\begin{abstract}
Elderly cases offered Takizawa-Program as one of the rehabilitation techniques were evaluated statistically. Initially we clarified the characteristics of the total FIM (Functional Independent Measure) score and the relation between the number of improved items and of worsened ones. Furthermore, we investigated the multidimensional relevance of 18 FIM items to explain the characteristics of improvement or aggravation clear, and obtained four factors by factor analysis and classified into six groups by cluster analysis, and then extracted some specific cases. Finally, we statistically verified the effect about the 18 FIM evaluation items using the t-test, a sign test and the Wilcoxon signed rank sum test, and several items in the FIM were turned out to be significantly effective.
\end{abstract}

Key words: Statistical evaluation, Takizawa-Program, Disabled Elderly, Rehabilitation, FIM (Functional independent measure)

\section{Introduction}

Up to this time, rehabilitation to the disabled elderly has been thought not to expect remarkable effects ${ }^{1)}$, ${ }^{2)}$. To such a way of thinking, Takizawa and others made a conclusion that certain measure of effect can be confirmed by applying the Takizawa-Program through their series of research ${ }^{3), 4), 5), 6)}$.

(Note)

Takizawa-Program: A way of rehabilitation which the disabled elderly use the devise, and the disabled elderly do artificial passive exercise by exercise of a unaffected side extremity of the handicapped person him/herself to exercise an affected side extremity, all in a sitting position.

In this research, we will try to find a pattern of effect on rehabilitation and then attempt the statistical evaluation by aiming at the cases who have enforced the Takizawa-Program in the Shonan-No-Oka health care facility for the elderly.

The evaluation of effect on rehabilitation was done to 51 people 4 times in total during June of 2000 to February of 2001. But a span of enforcing rehabilitation was uneven, and there exists a patient who has taken the evaluation once. Regarding the above-mentioned conditions, we have marked 44 examples who are able to measure the effect of rehabilitation throughout all the evaluation items as analytic objectives. Also, the evaluation scale of the rehabilitation is the band 6 item 18 based on FIM (Functional Independent Measure) shown in Table 1, and the difference between the first and final evaluation is calculated as an effect by the rehabilitation. The details about the evaluation measure of each item have been given in Endo and Takizawa ${ }^{7}$. 
Table 1 Evaluation scale: FIM

\begin{tabular}{|c|c|}
\hline [self-care] & [move] \\
\hline A. Eating & L. Walk \\
\hline B. Grooming & M. Stairs \\
\hline C. Bathing & [communication] \\
\hline D. Dressing - upper body & N. Comprehension (auditory) \\
\hline E. Dressing - lower body & O. Expression (verbal) \\
\hline F. Toileting & [social cognition] \\
\hline [toilet $]$ & P. Social interaction \\
\hline G. Bladder management & Q. Problem solving \\
\hline $\mathrm{H}$. Bowel management & R. Memory \\
\hline [transfer $]$ & \\
\hline I. Bed, chair, wheelchair & \\
\hline J. Toilet & \\
\hline K. Tub, Shower & \\
\hline
\end{tabular}

The main attributes of the evaluation objectives are as the following. Woman, more than $80 \%$, and the elderly over 75 years old take up $90 \%$.

(1) sex : 8 men, 36 women

(2) age composition :

4 people whose age is between 71 to 74 years old,

5 whose age is between 75 to 79 year old,

8 whose age is between 80 to 84 years old,

15 whose age is between 85 to 89 years old,

4 whose age is between 90 to 94 years old,

6 whose age is between 95 to 99 years old,

2 whose age is beyond 100 years old

\section{Characteristics of the total FIM score}

Before analyzing each character and relevance of FIM 18 items, we will explain the characteristics of the total FIM score. Therefore, we will investigate the relations between total score of 18 items and the number of improved or worsened items. Also, because the measurement of one item about a case was imperfect, 43 examples are the analytic objectives in this paragraph.

\subsection{The distribution of the total FIM score}

Figure 1 is the distribution of the total FIM score about the 43 examples. A part except for the score 0 is being drawn in the interval of 5 points. When it removes 2 or 3 singularly bad examples, the shape is very close to the normal distribution. As judged easily from the aspect of the distribution, it is difficult to confirm the effect on rehabilitation based on this total FIM score. Actually, as shown in the below paragraph, a mean of the total FIM score is 0.88 and the corresponding t-value is 0.45 , which statistically cannot reject 'no effect'. 
However, it has the possibility to overlook effective results in the judgment of only the total FIM score. It is because you can't judge the effects of 18 items independently, and the characteristics of each objective's effect can't be seen or the existence of the FIM score which is thought to be wrong itself is called in question as seen in Fig. 1. Other than that, many points to be examined are left.

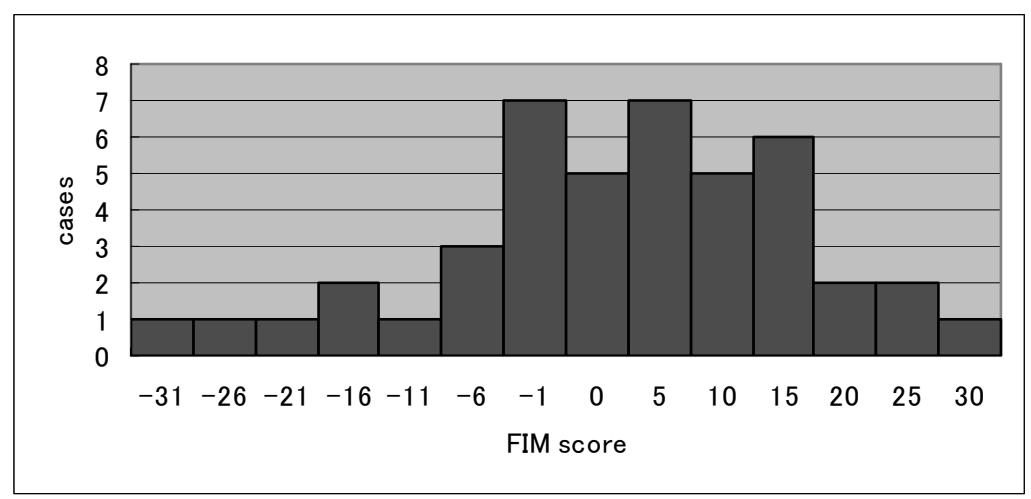

Fig. 1 Distribution of the total FIM score

\subsection{The total FIM score and the existence of the improved and worsened items}

When a total FIM score is plus, in case of minus as well, improved items and worsened items are mixed together in the 18 evaluation items. Under the condition of the total FIM score, the results of the existence of the improved or worsened items are shown in the Table 2.

Table 2 FIM total score and existence of improved and worsened items

\begin{tabular}{|c|c|c|c|c|}
\hline \multicolumn{3}{|c|}{ FIM total score } & \multicolumn{3}{|c|}{ improved / worsened } \\
\cline { 3 - 5 } \multicolumn{2}{|c|}{} & improved & invariability & worsened \\
\hline+ & 23 & - & 13 & 10 \\
\hline 0 & 5 & 4 & 1 & 4 \\
\hline- & 16 & 9 & 7 & - \\
\hline
\end{tabular}

Though the number of examples that the worsened items are observed is 10 , which is below $50 \%$ of the 22 who showed plus in a total score, 9 examples had the improved items observed, which marks more than $50 \%$ of the 16 who showed minus in a total score. Also, even if a synthetic score is 0 , it doesn't mean it didn't have any effect at all, and the improved items and the worsened items have both been observed. There always exist a few improvable items, even when a total score isn't good.

Furthermore, it is natural that the higher the total score is if there are more improved items, the lower the evaluation is if there are more worsened items or, less improved items. Figure 2 shows such relation concretely investigated. A horizontal axis is the value of the number of worsened items subtracted from the number of improved ones. As the relation between number of improved items and worsened items is very high in the part where a total score is plus, dispersion is big in the case of minus score. It shows that there are very bad total score cases even when the difference in the number of improved items and the number of worsened items is small, when a total score is a minus. This shows that the degree of the aggravation was extreme about the specific evaluation item.

Above characteristics will be overlooked, if observing only the total FIM scores. 


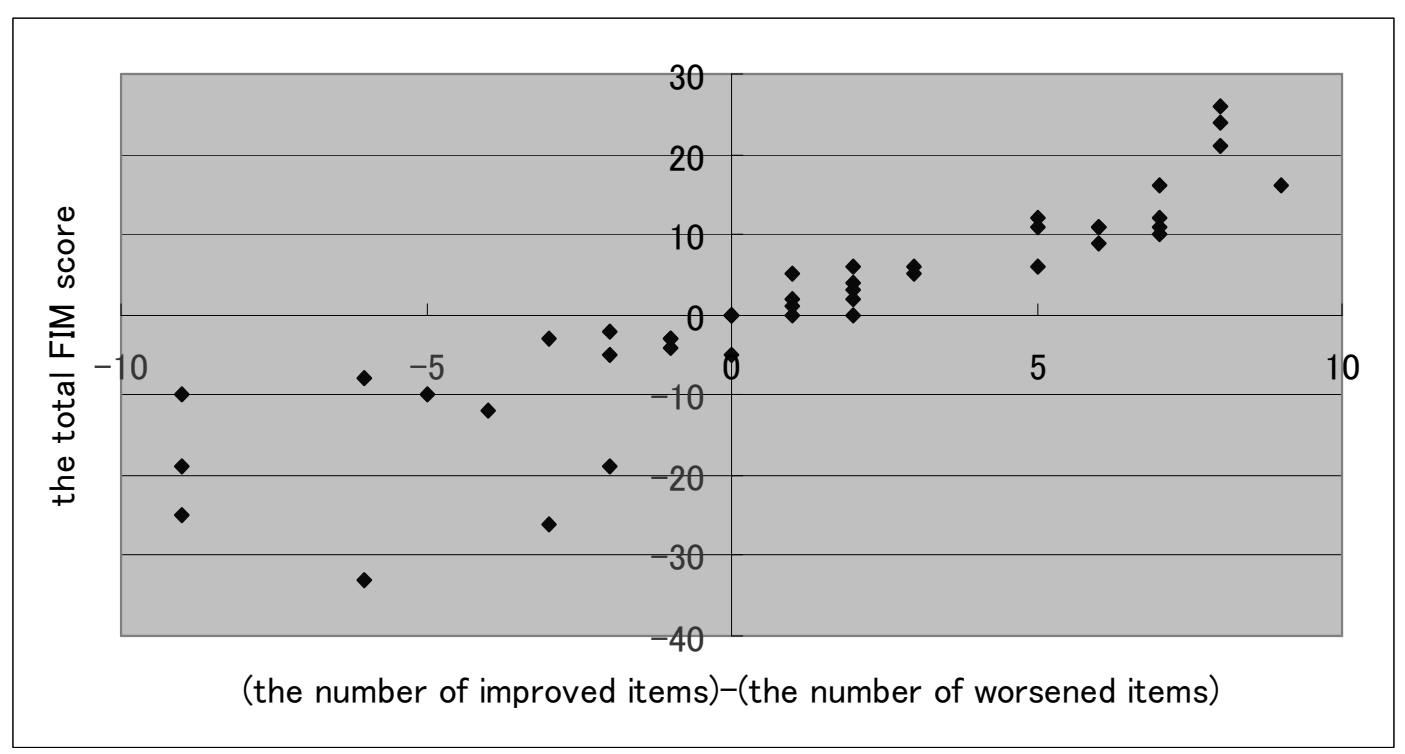

Fig.2 Relation of the FIM score and the number of improved, worsened items

\subsection{Pattern observing from relation between the number of improved items and the number of worsened items.}

Characteristic of each objective is observed from the relation between the number of improved items and of worsened ones. Figure 3 is the scatter diagram that shows the relevance of the number of improved items and of worsened ones. Observing the characteristics after dividing it into four groups as in Fig. 3, it is possible to point out the following remarks.

(i) Group C is a group which is far from the original point and near to the horizontal axis, and it is the group in which the effect on improvement is significantly remarkable. The group is included a few number of worsened items, but on the other hand, a lot of improved items exist.

(ii) Group A is exactly in the counter situation of a group C, also far from the original point, near a vertical axis. The group has included a few improved items, but a lot of worsened items exist.

(iii) Group D is a group that is distributed near the original point and it is hard to assess the effect of improvement. Either the improved item or the worsened item was a few.

(iv) The group B, which is near a diagonal line, has opposition between the number of improved items and of worsened ones, and also is far from original point which makes it hard to identify an effect. It is needed to examine contents and causes of each improved and worsened items.

From a result of examinations mentioned above, it is understood that there are various aspects of effect on rehabilitation, which cannot be judged only by the total FIM scores. Especially, attention is needed on the analysis of the rehabilitation effect due to existence of the examples that shows different change from most other examples. 


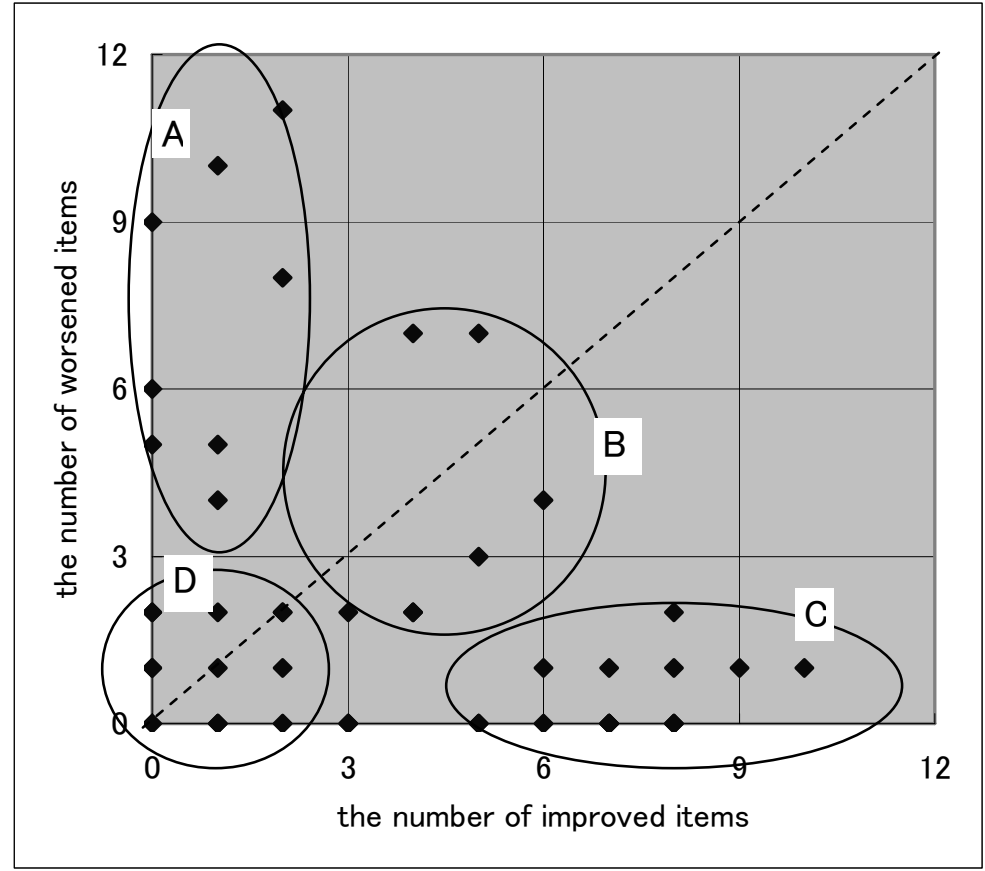

Fig. 3 Relevance of the number of improved items and of worsened ones

\section{The multivariable characters of effect on improvement}

In the former paragraph, the total FIM score or the number of improved and of worsened items were focused to investigate an effect of the rehabilitation. Here, we investigate the multidimensional relevance of 18 items to explain the characteristics of improvement or aggravation clear. In order to do so, we tried the classification of the case by extracting a pattern of rehabilitation effects through both factor analysis and cluster analysis.

\subsection{Factor analysis}

Factor analysis was done to 16 items, excluding Social interaction and Memory. The reason for excluding 2 items is that their communalities were very low by comparing to the other items.

Table 3 shows a factor matrix after the rotation about four factors extracted by principal factor method. The rate of contribution by the four factors is about $60 \%$ of the whole, and the 1 st factor covers almost $50 \%$ of it. The rates of contribution of the other 3 factors are about the same.

Each factor can be interpreted as follows by observing the characteristics of the factor matrix.

(i) The $1^{\text {st }}$ factor is mainly related to a rehabilitation of the lower extremities, and it shows high mutual relation with most of the item of Walk or Toileting. From here onwards, it is suitable to define the 1st factor as 'a physical function factor'. Also, it has the explanation power of $30 \%$ of the total dispersion, and is the best factor that contributes in distinguishing an effect of rehabilitation. But it is noticeable that the two items of Tub-Shower and Stairs, which are in the same evaluation group, are independent as the $4^{\text {th }}$ factor. These items may need a little higher technology different from other items.

(ii) The $2^{\text {nd }}$ factor is a factor which can be specialized in the item of Comprehension(auditory) and Expression(verbal) in the communication group. In other words it can be judged as 'a factor about the 
communication' because correlation with the evaluated item, which relates with other people excepting for oneself, is high. This factor has a strong relationship with Eating in Self-care group. The relation between Eating and Communication is very interesting.

(3) The $3^{\text {rd }}$ factor has high correlation with the items that are conscious of the appearance, such as Grooming, Bathing and Dressing-upper body and how they are looked from others. So, it can be recognized as 'a others consciousness factor'.

Table 3. Factor analysis

\begin{tabular}{|c|c|c|c|c|}
\hline \multirow[b]{2}{*}{ FIM item } & \multicolumn{4}{|c|}{ Factor } \\
\hline & 1 & 2 & 3 & 4 \\
\hline \multicolumn{5}{|l|}{ (self-care) } \\
\hline A. Eating & -0.058 & 0.556 & 0.327 & -0.085 \\
\hline B. Grooming & 0.012 & 0.224 & 0.770 & -0.172 \\
\hline C. Bathing & 0.395 & -0.054 & 0.562 & 0.005 \\
\hline D. Dressing - upper body & 0.334 & 0.148 & 0.463 & 0.011 \\
\hline E. Dressing - lower body & 0.728 & -0.033 & 0.237 & 0.107 \\
\hline F. Toileting & 0.975 & -0.012 & 0.007 & -0.040 \\
\hline \multicolumn{5}{|l|}{ (toilet) } \\
\hline G. Bladder management & 0.603 & 0.135 & -0.196 & -0.003 \\
\hline H. Bowel management & 0.712 & 0.006 & -0.114 & -0.320 \\
\hline \multicolumn{5}{|l|}{ (transfer) } \\
\hline I. Bed, chair, wheelchair & 0.833 & 0.007 & 0.138 & 0.177 \\
\hline J. Toilet & 0.896 & 0.013 & 0.099 & 0.113 \\
\hline K. Tub, Shower & 0.112 & 0.024 & -0.065 & 0.707 \\
\hline \multicolumn{5}{|l|}{ (move) } \\
\hline L. Walk & 0.665 & 0.208 & 0.129 & 0.201 \\
\hline M. Stairs & 0.151 & -0.011 & -0.079 & 0.792 \\
\hline \multicolumn{5}{|l|}{ (communication) } \\
\hline N. Comprehension (auditory) & 0.152 & 0.604 & -0.285 & 0.009 \\
\hline O. Expression (verbal) & 0.069 & 0.553 & 0.151 & 0.044 \\
\hline \multicolumn{5}{|l|}{ (social cognition) } \\
\hline P. Social interaction & - & - & - & - \\
\hline Q. Problem solving & 0.115 & 0.662 & 0.055 & 0.016 \\
\hline R. Memory & - & - & - & - \\
\hline eigen value & 4.638 & 1.557 & 1.500 & 1.367 \\
\hline rate of contribution & 29.0 & 9.7 & 9.4 & 8.5 \\
\hline cumulative rate of contribution & 29.0 & 38.7 & 48.1 & 56.6 \\
\hline
\end{tabular}

\subsection{Cluster analysis}

We have done cluster analysis on extracted 4 factors. We classified consequently into 6 clusters and formed a position of center of each factor, the number of cases and the total FIM score by the case into a line as shown in Table 4 . Four clusters excluding the $3^{\text {rd }}$ and the $6^{\text {th }}$ extracted examples that showed a very peculiar response judging from the number of the cases.

To conclude the characteristics of clusters, it is as follows.

(1) The $1^{\text {st }}$ cluster shows that it extracted the two examples of which evaluation of the $4^{\text {th }}$ factor, the Tub, Shower and Stairs items have widely worsened.

(2) The $2^{\text {nd }}$ and the $3^{\text {rd }}$ cluster is characterized by the $1^{\text {st }}$ factor as the physical function factor concerning Walk and Toileting. The $2^{\text {nd }}$ cluster extracts two examples whose degree of aggravation was big. On the other hand, the $3^{\text {rd }}$ cluster classifies nine examples whose effect on improvement was huge. These nine examples are equivalent in about $20 \%$ of the whole. 
(3) The $4^{\text {th }}$ cluster includes only one peculiar example, which shows that the degree of aggravation on both the $2^{\text {nd }}$ factor and the $3^{\text {rd }}$ factor were high. In other words, it is the case that the factors of 'communication', 'other consciousness' and so on became very much worse for the evaluation period. Also the total FIM score shows the volume of the degree of the aggravation.

(4) The $5^{\text {th }}$ cluster includes three examples, where only the $3^{\text {rd }}$ factor worsened different from the $4^{\text {th }}$ cluster. As for one example of the three, the total FIM score is a plus. The reason is that several items other than the $3^{\text {rd }}$ factor were improved.

(5) The $6^{\text {th }}$ cluster which includes about $60 \%$ of the total numbers of cases, shows average tendency on each factor. About the effect in the rehabilitation period, it is imagined that the degrees of aggravation or improvement as well were gentle. Actually, most of the total FIM scores are within range of \pm 10 except for one example which degree of aggravation is high (score -19).

Table 4. Cluster analysis based four factors

\begin{tabular}{|c|c|c|c|c|c|l|}
\hline \multirow{2}{*}{ cluster } & \multicolumn{3}{|c|}{$\begin{array}{c}\text { a position of a center by } \\
\text { each factor }\end{array}$} & \multicolumn{2}{|c|}{ case information } \\
\cline { 2 - 7 } & 1 & 2 & 3 & 4 & $\begin{array}{l}\text { number } \\
\text { of case }\end{array}$ & total FIM score \\
\hline 1 & -0.323 & 0.165 & 0.614 & -3.325 & 2 & $-12,0$ \\
\hline 2 & -3.150 & 0.335 & 0.496 & 0.729 & 2 & $-33,-26$ \\
\hline 3 & 1.299 & 0.118 & 0.144 & 0.071 & 9 & $\begin{array}{l}3,9,11,12,16 \\
16,21,24,26\end{array}$ \\
\hline 4 & -0.186 & -3.657 & -1.670 & 0.423 & 1 & -25 \\
\hline 5 & -0.002 & 0.475 & -2.520 & 0.068 & 3 & $-19,-10,6$ \\
\hline & & & & & & $\begin{array}{l}-19,-10,-8,-5 \\
-5,-4,-3,-3,-3 \\
\end{array}$ \\
\hline 6 & -0.175 & 0.007 & 0.220 & 0.151 & 26 & $\begin{array}{l}-2,0,0,0,0,1 \\
2,2,4,5,6,6 \\
10,11,11,11,12\end{array}$ \\
\hline
\end{tabular}

As written above, three factors excluding the $1^{\text {st }}$ factor have extracted the cases that showed peculiarly big aggravation, namely, on which improvement of physical function by the rehabilitation could not be observed.

\section{The effect analysis of the 18 FIM items}

In this paragraph, we will statistically verify the effect about the 18 FIM evaluation items and the total score. The existence of the cases, which show a peculiar change, became evident from the examination results in the previous sections. It is an important judgment whether to include them in analysis. However, we analyze the case with all the data considering reliability, and compared with the case excluded two examples based on each observer's clinical decision rather than statistical decision.

The following three methods are adopted as a testing method. Furthermore, the test statistics and the corresponding p-values were calculated on every evaluation item.

(a) The $t$-test (of paired data) to the mean of the FIM score as a degree of improvement,

(b) A Sign test which has analyzed the existence of improvement,

(c) The Wilcoxon signed rank sum test (noted 'Sgn Rank') as the middle method of above two. 
Table 5 is the result when all the data were used and Table 6 is when two examples were excluded. Followings can be pointed out from these tables.

(i) Rehabilitation effects couldn't be detected in any case from the total FIM score.

(ii) But Walk, Wheelchair was judged as effective in every test examining by items and using all the data.

Though effect wasn't admitted with Bowel Management by the $t$-test, it was admitted by the Sign test.

(iii) Others than that, effects are also admitted with Toileting and Comprehension(auditory) depending on the way of test.

(iv) In Table 6 which has excluded the special case, effect is also admitted with Comprehension(auditory) in addition to Walk, Wheelchair.

(v) Also, the possibility of effects is rising with Toileting and Bowel Management.

It is important to observe the data minutely from various aspects and to examine the effect through not only general effect but also partial effect in such an analysis that has a few targets. Actually, even though effects weren't seen statistically when evaluating by total FIM score, they were shown in some FIM items. Also we got knowledge of the possibility that the effects on some items might be evaluated statistically by adding the number of cases.

Table 5. Test result of effect on improvement -all the examples

\begin{tabular}{|c|c|c|c|c|c|c|c|c|c|c|c|}
\hline \multirow[b]{2}{*}{ FIM Item } & \multicolumn{3}{|c|}{$\begin{array}{l}\text { existence of } \\
\text { improvement }\end{array}$} & \multicolumn{2}{|c|}{$\begin{array}{l}\text { the degree of } \\
\text { improvement }\end{array}$} & \multicolumn{6}{|c|}{ test } \\
\hline & - & 0 & + & mean & S.D. & $t$ & $\begin{array}{c}p \\
\text { value }\end{array}$ & Sign & $\begin{array}{c}p \\
\text { value }\end{array}$ & $\begin{array}{l}\text { Sgn } \\
\text { Rank }\end{array}$ & $\begin{array}{c}p \\
\text { value }\end{array}$ \\
\hline \multicolumn{12}{|l|}{ (self-care) } \\
\hline A. Eating & 5 & 34 & 5 & -0.07 & 0.95 & -0.48 & 0.636 & 0 & 1.000 & -2 & 0.865 \\
\hline B. Grooming & 8 & 29 & 7 & -0.41 & 1.83 & -1.48 & 0.146 & -0.5 & 1.000 & -18 & 0.317 \\
\hline C. Bathing & 9 & 21 & 14 & 0.36 & 1.78 & 1.36 & 0.182 & 0.25 & 0.405 & 50 & 0.122 \\
\hline D. Dressing - upper body & 8 & 26 & 10 & -0.05 & 1.52 & -0.20 & 0.844 & 1 & 0.815 & 3.5 & 0.881 \\
\hline E. Dressing - lower body & 8 & 26 & 10 & 0.11 & 1.78 & 0.42 & 0.674 & 1 & 0.815 & 10 & 0.674 \\
\hline F. Toileting & 4 & 28 & 12 & 0.25 & 1.75 & 0.95 & 0.350 & 4 & 0.076 & 24.5 & 0.214 \\
\hline \multicolumn{12}{|l|}{ (toilet) } \\
\hline G. Bladder management & 9 & 28 & 7 & -0.32 & 1.23 & -1.71 & 0.095 & -1 & 0.804 & -29.5 & 0.118 \\
\hline H. Bowel management & 3 & 28 & 12 & -0.16 & 1.65 & 0.65 & 0.520 & 4.5 & 0.035 & 21.5 & 0.233 \\
\hline \multicolumn{12}{|l|}{ (transfer) } \\
\hline I. Bed, chair, wheelchair & 9 & 22 & 13 & 0.34 & 1.57 & 1.44 & 0.157 & 2 & 0.525 & 38.5 & 0.204 \\
\hline J. Toilet & 9 & 24 & 11 & 0.18 & 1.57 & 0.77 & 0.448 & 1 & 0.824 & 24 & 0.378 \\
\hline K. Tub, Shower & 9 & 31 & 4 & -0.20 & 1.19 & -1.14 & 0.262 & -2.5 & 0.267 & -14.5 & 0.326 \\
\hline \multicolumn{12}{|l|}{ (move) } \\
\hline L. Walk & 2 & 27 & 15 & 0.57 & 1.68 & 2.25 & 0.030 & 6.5 & 0.002 & 48 & 0.023 \\
\hline M. Stairs & 5 & 36 & 3 & -0.16 & 0.91 & -1.16 & 0.254 & -1 & 0.727 & -7.5 & 0.375 \\
\hline \multicolumn{12}{|l|}{ (communication) } \\
\hline N. Comprehension (auditory) & 1 & 36 & 7 & 0.30 & 1.07 & 1.83 & 0.074 & 3 & 0.070 & 12.5 & 0.102 \\
\hline O. Expression (verbal) & 5 & 33 & 6 & 0.00 & 1.57 & 0.00 & 1.000 & 0.5 & 1.000 & 0 & 1.000 \\
\hline \multicolumn{12}{|l|}{$\begin{array}{l}\text { (social cognition) } \\
\end{array}$} \\
\hline P. Social interaction & 3 & 39 & 2 & -0.16 & 1.20 & -0.88 & 0.384 & -0.5 & 1.000 & -3 & 0.500 \\
\hline Q. Problem solving & 4 & 31 & 9 & 0.07 & 1.42 & 0.32 & 0.752 & 2.5 & 0.267 & 13 & 0.390 \\
\hline R. Memory & 5 & 29 & 10 & 0.00 & 1.22 & 0.00 & 1.000 & 2.5 & 0.302 & 4.5 & 0.829 \\
\hline $\begin{array}{r}\text { FIM total } \\
\end{array}$ & 16 & 5 & 22 & 0.88 & 12.83 & 0.45 & 0.654 & 3 & 0.418 & 58 & 0.407 \\
\hline
\end{tabular}


Table 6. Test result of effect on improvement -except two examples $(\mathrm{N}=42)$

\begin{tabular}{|c|c|c|c|c|c|c|c|c|c|c|c|}
\hline \multirow[b]{2}{*}{ FIM Item } & \multicolumn{3}{|c|}{\begin{tabular}{|l} 
existence of \\
improvement
\end{tabular}} & \multicolumn{2}{|c|}{$\begin{array}{l}\text { the degree of } \\
\text { improvement }\end{array}$} & \multicolumn{6}{|c|}{ test } \\
\hline & - & 0 & + & mean & S.D. & $t$ & $\begin{array}{c}p \\
\text { value }\end{array}$ & Sign & $\begin{array}{c}p \\
\text { value }\end{array}$ & $\begin{array}{l}\text { Sgn } \\
\text { Rank }\end{array}$ & $\begin{array}{c}p \\
\text { value }\end{array}$ \\
\hline \multicolumn{12}{|l|}{ (self-care) } \\
\hline A. Eating & 4 & 33 & 5 & 0.02 & 0.75 & 0.21 & 0.838 & 0.5 & 1.000 & 3 & 0.773 \\
\hline B. Grooming & 7 & 28 & 7 & -0.29 & 1.66 & -1.12 & 0.270 & 0 & 1.000 & -10.5 & 0.534 \\
\hline C. Bathing & 8 & 20 & 14 & 0.40 & 1.81 & 1.45 & 0.155 & 3 & 0.286 & 50.5 & 0.095 \\
\hline D. Dressing - upper body & 6 & 26 & 10 & 0.10 & 1.34 & 0.46 & 0.648 & 2 & 0.455 & 14.5 & 0.461 \\
\hline E. Dressing - lower body & 6 & 26 & 10 & 0.26 & 1.62 & 1.05 & 0.302 & 2 & 0.455 & 19 & 0.353 \\
\hline F. Toileting & 3 & 27 & 12 & 0.40 & 1.50 & 1.75 & 0.088 & 4.5 & 0.035 & 32.5 & 0.067 \\
\hline \multicolumn{12}{|l|}{ (toilet) } \\
\hline G. Bladder management & 7 & 28 & 7 & -0.24 & 1.19 & -1.30 & 0.200 & 0 & 1.000 & -17.5 & 0.265 \\
\hline H. Bowel management & 2 & 27 & 12 & 0.32 & 1.37 & 1.48 & 0.146 & 5 & 0.013 & 29 & 0.076 \\
\hline \multicolumn{12}{|l|}{\begin{tabular}{|c|} 
(transfer) \\
\end{tabular}} \\
\hline I . Bed, chair, wheelchair & 8 & 21 & 13 & 0.40 & 1.56 & 1.68 & 0.101 & 2.5 & 0.383 & 44 & 0.114 \\
\hline J. Toilet & 8 & 23 & 11 & 0.26 & 1.53 & 1.11 & 0.274 & 1.5 & 0.638 & \begin{tabular}{|l|}
31 \\
\end{tabular} & 0.213 \\
\hline K. Tub, Shower & 9 & 29 & 4 & -0.21 & 1.22 & -1.14 & 0.262 & -2.5 & 0.267 & -14.5 & 0.326 \\
\hline \multicolumn{12}{|l|}{$\begin{array}{r}\text { (move) } \\
\end{array}$} \\
\hline L. Walk & 1 & 26 & 15 & 0.71 & 1.47 & 3.15 & 0.003 & 7 & 0.001 & 55.5 & 0.002 \\
\hline M. Stairs & 5 & 34 & 3 & -0.17 & 0.93 & -1.16 & 0.255 & -1 & 0.727 & -7.5 & 0.375 \\
\hline \multicolumn{12}{|l|}{\begin{tabular}{|l} 
(communication) \\
\end{tabular}} \\
\hline N. Comprehension (auditory) & 0 & 35 & 7 & 0.36 & 1.03 & 2.24 & 0.030 & 3.5 & 0.016 & 14 & 0.016 \\
\hline O. Expression (verbal) & 4 & 32 & 6 & 0.07 & 1.54 & 0.30 & 0.765 & 1 & 0.754 & 3.5 & 0.787 \\
\hline \multicolumn{12}{|l|}{$\begin{array}{l}\text { (social cognition) } \\
\end{array}$} \\
\hline P. Social interaction & 3 & 37 & 2 & -0.17 & 1.23 & -0.88 & 0.384 & -0.5 & 1.000 & -3 & 0.500 \\
\hline Q. Problem solving & 3 & 31 & 8 & 0.19 & 1.09 & 1.14 & 0.263 & 2.5 & 0.227 & 15.5 & 0.172 \\
\hline R. Memory & 5 & 28 & 9 & -0.02 & 1.24 & -0.12 & 0.902 & 2 & 0.424 & 1.5 & 0.954 \\
\hline $\begin{array}{r}\text { FIM total } \\
\end{array}$ & 14 & 5 & 22 & 2.34 & 11.18 & 1.34 & 0.188 & 4 & 0.243 & 94.5 & 0.140 \\
\hline
\end{tabular}

\section{Conclusion}

There are cases whose changes occur peculiarly during the rehabilitation term because they had various difficulties. Even under such conditions, we could confirm that the Takizawa-Program for the disabled elderly was significantly effective on some FIM evaluation items statistically.

Of course, the rehabilitation can't be effective to all the aged patients. It was suggested that there is a group whose improvement seems difficult and they showed a peculiar response to a certain item trough this study. Therefore, when we find out those patterns at the early stage on rehabilitation of them it will be suitable for us to help or care for them by other means.

Furthermore, we will propose more effective rehabilitation method and a process in our future research by examining many more cases and investigating the detail of cases while effect is hardly shown. It relates to verify reliability of the results on this study. 


\section{References}

1) Kimura, T. (1997). The rehabilitation for the spinal injury in the National Rehabilitation Center for the Disabled. Proc. of World health organization International Seminar Report, pp. 57-60.(Japanese document)

2) Tanaka, E., Kitaoka, T. (1998). The improvement of ADL due to rehabilitation at our facilities. Proc.of The 35th Japanese Association of Rehabilitation Medicine Conference (or JARMC), pp. 281. Aomori.

3) Kimura T., Takizawa S. (2001). Research report for ADL improvement and independence of the disabled elderly patients in lower extremity's fracture (Association for Technical Aid / Grant for Welfare devices investigation research). CIVIL Publishing.

4) Kimura T. (supervision) (2002). From care reliance to independence (the first roll). CIVIL Publishing.

5) Takizawa S., Kimura T., Kijima H., Okamoto Y., Nagaoka K., Morita Y., Endo S. and Takizawa K. (2001). Re-acquirement of walking from bedridden by the motivative exercise and proposition of the solution to the aging crisis. Paper presented at: the 1st ISPRM. Amsterdam. July 13.

6) Takizawa S., Kimura T., Kijima H., Okamoto Y., Nagaoka K., Morita Y., Endo S., Nagasawa H., Makita M. and Takizawa K. (2001). Biophilia rehabilitation and proposition of the solution to the aging crisis. The 1st ISPRM. Monduzzi Editore. Ferrarese, 729-736.

7) Endo S., Takizawa S. (2002). Simple ADL Evaluation Chart according to the FIM standard (in Japanese). Proc of Biophilia Rehabilitation Conference in Keio University, 29-30. 